Mitchell ABOULAFIA, Transcendence. On selfdetermination and Cosmopolitanism

Stanford University Press, Standford, 2010

Roberto Frega

\title{
CpenEdition
}

Electronic version

URL: http://journals.openedition.org/ejpap/804

DOI: 10.4000/ejpap.804

ISSN: 2036-4091

Publisher

Associazione Pragma

Electronic reference

Roberto Frega, " Mitchell aBoulafia, Transcendence. On self-determination and Cosmopolitanism », European Journal of Pragmatism and American Philosophy [Online], IV - 1 | 2012, Online since 23 July 2012, connection on 24 September 2020. URL : http://journals.openedition.org/ejpap/804 ; DOI : https://doi.org/10.4000/ejpap.804

This text was automatically generated on 24 September 2020

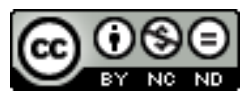

Author retains copyright and grants the European Journal of Pragmatism and American Philosophy right of first publication with the work simultaneously licensed under a Creative Commons AttributionNonCommercial-NoDerivatives 4.0 International License. 


\section{Mitchell aBOULAFIA, Transcendence. On self-determination and Cosmopolitanism}

Stanford University Press, Standford, 2010

Roberto Frega

\section{REFERENCES}

Mitchell ABOULAFIA, Transcendence. On self-determination and Cosmopolitanism, Stanford University Press, Standford, 2010

1 Mitchell Aboulafia's new book pursues previous inquiries carried forth by the author on the notion of Cosmopolitanism. Whereas so far Aboulafia had mostly developed this notion with reference to Mead, in this book he weaves together the different strands of a Euro-American philosophical conception of cosmopolitanism, taken to be the core of a moral, social, and political vision centered around the modern ideas of autonomy and of individual and collective self-realization.

2 Aboulafia's attempt is valuable for many reasons, not lastly because he avoids the standard reading of cosmopolitanism as a merely political virtue, and locates it at the crossroad of individual and collective processes of identity-making. He suggests we understand cosmopolitanism as being at the same time a private and a public virtue, a capacity for self-transcendence that does not require self-negation. Developing a deeply Meadian intuition, Aboulafia conceives of cosmopolitanism as the outcome of a process of personal growth in which the ego formation is conceived as a process of ego enlargement, where self-determination is not conceived merely in terms of separation of the self from the other, but in terms of circles of progressive enclosure with the world and self-enlargement. As Hannah Arendt would have said, it is by enlarging its mentality that the self realizes its best aspirations. Although Aboulafia tends to emphasize the moral, psychological, and sociological dimensions of transcendence and 
cosmopolitanism, these virtues have also deep and important political implications, which in this book tends to remain in the background.

Aboulafia philosophical thesis is clear and steadfast: we should avoid opposing selfdetermination and self-transcendence, and come rather to see self-transcendence as a step of self-realization. This is one of the major implications of G. H. Mead's philosophy, an implication that is particularly momentous in a political culture that continues to oppose the private to the public, values to norms, the ethical to the moral. Aboulafia's book, although not directly dealing with these issues, urges us implicitly to dismiss these too hastily accepted dogmas of contemporary political theory, inviting us to rethink our identity across these theoretical borders.

Consistently with these broad theoretical premises, Aboulafia sides with Charles Taylor's anti-essentialist expressivism and against Gottfried von Herder's essentialist expressivism. This is no surprise, especially if seen against the pragmatist and existentialist background that Aboulafia claims for his undertaking. Indeed, both these traditions have explicitly rejected all forms of essentialism, and advocated a reconstructive and creative conception of the self as an essentially social yet not completely socialized artifact. Put in different terms - more faithful to Aboulafia's pragmatist than existentialist roots - the book tries to articulate a vision of social life in which social determination and individual creativity are two strongly interdependent faces of the same phenomenon.

With the exception of excerpts from chapters 3,4 , and 5, the book consists of new materials. The book is composed of eight chapters divided into three parts, the first focusing on the individual dimension of transcendence, the second on the collective dimension of cosmopolitanism, whereas the third tackles some contemporary debates in the light of the theoretical perspective advanced in parts one and two. In what follows I will shortly discuss a selection of these chapters.

6 The book's first chapter is the most explicit in bringing pragmatism and existentialism in conversation. One may be puzzled by Aboulafia's decision to leave to Richard Rorty the pride of place of "representative" of the pragmatist army in his undertaking, as well as of the fruitfulness of the extended comparison between Richard Rorty and JeanPaul Sartre. However, if we read the chapter as an opening intended to suggest an area of resonance between the two traditions, Aboulafia's strategy appears convincing. Indeed, Rorty plays here the role of a facilitator in introducing one of the two key themes of the book, and in staging a bridge between pragmatism and existentialism as philosophical traditions committed to anti-essentialism, that is to say to a conception of individuals and cultures as being defined by their capacity to self-transcendence. This point should be kept in mind if we are to avoid overprizing the role played by Rorty in Aboulafia's account. Indeed, since chapter two Aboulafia set to a more ambitious task as he tries to bring closer Sartre and Dewey's perspectives, the huge difference between their philosophical projects notwithstanding.

7 Aboulafia is aware of the daringness of his proposal, and draws on selected materials from both authors to show some possible lines of convergence uniting the two otherwise deeply diverging philosophical projects. The thesis that, according to Aboulafia, best express the affinities between pragmatism and existentialism - and more precisely between Dewey and Sartre - is that of the practical nature of freedom, that is to say the idea that freedom can be attained only in the dimension of practical life and its contextual undertakings. One may doubt whether the rather pragmatized 
existentialism that Aboulafia has to offer would satisfy the existentialist readerships. Certainly the strategy proves fruitful when seen in the reverse direction, as our understanding of Dewey cannot but benefit from a reading that adequately emphasizes the importance of non-instrumental, perfectionist, and even tragic dimensions of ethical experience.

Chapters 4 and 5 constitute the core of the book. In chapter 4 Aboulafia develops the main philosophical implications of Mead's kind of cosmopolitanism. Aboulafia starts with a challenging philosophical thesis; namely, that cosmopolitanism should be read not merely as part of a theory of ethical life but also as the solution envisaged by Mead to define our moral obligations. Indeed, Aboulafia believes that Mead's theory of the generalized other is intended to explain self-realization as well as autonomy: what is produced by the dialectical interplay of self and other is a social personality that encompasses values as well as norms, expressive preferences as well as duties. This "enlarged mentality" is not the result of a passive absorption by the individual of existing social norms and values, but is the product of a ceaseless constructive appropriation of diverse normative standpoints.

Seen in this Meadian perspective, cosmopolitanism is at the same time an ethical and a political ideal: it provides us with a normative standard for devising ethical progress and with a normative standard for assessing political practice. Mead opposes cosmopolitanism to selfishness as two images of the self: the first confines the self to a restricted identity, in which only a limited number of small generalized others is involved, whereas the second is characterized by the capacity to encompass in one's own identity the largest number of generalized others. Here Aboulafia marks a point that is central to his project: the true cosmopolitan is not an avatar of the liberal ironist that looks at the world from the vantage point of a universal and abstract view from nowhere. Rather, the cosmopolitan is the person that has included in his own rich identity a multiplicity of other collective identities. In this way, the universal point of view of humanity does not replace the plurality of other collective identities in the cosmopolitan mind, but is rather added to them. Therefore, the enlargement is not attained through a process of abstraction and generalization, but rather through a process of progressive inclusion, through acquaintance with an ever larger number of generalized others.

10 That Mead is following a path orthogonal to that followed by mainstream contemporary philosophy can be seen in the fact that he is unwilling to uncouple selfrealization from autonomy, morality from ethicity. As Aboulafia explains at p. 76, "to adequately respond to others, we must also possess a sense of obligation." This fact explains why for Mead cosmopolitanism can be at the same time a moral virtue and a political standard, why it can ground our ethical standing as well as our moral obligations toward others. Although Aboulafia does not fully develop the implications of Mead's theory of the generalized other for a theory of justice, he deploys the basis for such a project by showing how sympathy and the mechanism of the generalized other work together in the genesis of moral duties, how ethical habits are necessary in order to instantiate socially shared moral orders. As Aboulafia perceptively shows, according to Mead the capacity to identify with a plurality of generalized others, to imagine their forms of life, to sympathize with them is a precondition of our capacity to devise universal duties: we need to feel our bond with others before we understand 
what we owe them. This is at least one of the possible ways to link values to duties, selfrealization to autonomy.

11 In the following chapter Aboulafia extends his argument through the examination of W.E. B. Du Bois writings on the negro condition. Aboulafia shows how Du Bois's arguments provide a critique of racism that is in line with the Meadian understanding of cosmopolitanism. The chapter usefully traces Du Bois's cosmopolitan conception of the social self to his formative years as a student of William James, reminding us in passing the role played by James's conception of the social self for the whole pragmatist tradition. As Aboulafia aptly remarks, the experience of racism shows us the dark side of the social constitution of the self. Indeed, the idea that "impartiality is nurtured through individuals taking multiple perspectives, must come to terms with the reality that seeing oneself through the eyes of others can in fact be a damaging experience" (99). Hence, as a consequence, the paradoxically privileged position that is open to the victims of oppression, as "those who have a double-consciousness are in a unique position to achieve the impartiality of the spectator because of a heightened awareness of otherness and multiplicity" (ibid.).

12 The third section of the book is quite different from the former two, as it is meant to test the theory of self-transcendence and cosmopolitanism previously articulated through three different strategies. The first is mainly negative and consists in showing that Neil Gross's attempt at interpreting Rorty's thought and career fails precisely for an excessive commitment to determinism that Aboulafia explains in terms of an inadequate consideration of the role of transcendence in the formation of identity. Aboulafia approaches Gross's biography of Richard Rorty from the standpoint of Mead's social psychology, and in particular of Mead's notion of the generalized other, that Gross utilizes as part of his explanation of "the making" of Richard Rorty as a philosopher. If the aim of Gross's theory was merely to state that intellectuals as well as all other human beings produce self-concepts in order to obtain self-consistency, one would be pressed to ask for the relevance of the topic for Aboulafia's book. The answer to this question has to be found in Aboulafia's persuasion that self-transcendence is a necessary constituent of human identity, and that its neglect exposes to failures in understanding human agency. In the case of Gross's account of Rorty, Aboulafia wants to show that short of an adequate understanding of this dimension, Gross is inevitably forced to explain the intellectual production of Rorty in reductionist terms.

What Aboulafia questions therefore is not the specific interpretation of Richard Rorty offered by Neil Gross, but rather the analytical pattern through which Gross explains Rorty's intellectual achievements in terms of social determinants rather than in terms of a more individual-centered process of self-transformation through social interaction. As Aboulafia shows, an explanatory model more sensitive to Mead's social psychology would have helped Gross to avoid the same errors he imputed to Bourdieu's sociology of intellectuals.

14 Aboulafia leaves to his last chapter, titled "What if Hegel's master and slave were women?," the task to bring his book to a close under the auspices of Hegel, whose influence on the pragmatists and the existentialists explains the family resemblances between these two traditions. It is notably Hegel's phenomenology of Spirit that, according to Aboulafia, provides the theoretical reference for most of contemporary attempts at conceptualizing transcendence as a distinctive feature of the human self both in Europe and in the United States. Although it is not the aim of the chapter to 
discuss in details the direct influence of Hegel's thought in contemporary theories of transcendence, we are constantly reminded that a correct appraisal of the identities and differences that unite and divide the various strand of the Euro-American philosophy demands a previous clarification of the different ways of inheriting from Hegel and more generally from German Idealism. But Aboulafia goes a step further, joining those thinkers that, like Joseph Margolis, have recently insisted that the pragmatists have conceived of this inheritance in the terms of what C. S. Peirce once termed a Darwinization of Hegel matched with a Hegelianization of Darwin. This is particularly true of John Dewey and George H. Mead. In this chapter Aboulafia shows how Mead's social psychology completes and supersedes Hegel's philosophy of consciousness, socializing and naturalizing the Master-Slave dialectics. And it is from the Meadian vantage point that Aboulafia, via a discussion of Miller's Toward a New Psychology of Women, tries to bring the question of gender within the bounds of his account of self-transcendence and cosmopolitanism, in a way not dissimilar from how W.E. B. Du Bois had achieved to bring the color line at the heart of western universalism.

To conclude, Aboulafia's book provides an insightful exploration of a central theme of contemporary philosophy, showing the distinctive pragmatist contribution to its unfolding, while illustratiting at the same time the rich network of direct and indirect connections and resonances that weave together the American and the European philosophies of the Twentieth Century. Although the book suffers from a certain fragmentariness which in the end makes difficult for the reader to grasp the exact views of Aboulafia about self-transcendence and cosmopolitanism, it is certainly welcomed for his successful attempts at showing the lasting philosophical importance of G. H. Mead and at bringing a step further our awareness that American and European philosophy are different branches stemming from the same common tree.

\section{AUTHORS}

\section{ROBERTO FREGA}

CEMS/EHESS

fregarob[at]gmail.com 